\section{Virtually better}

$\mathrm{A}$ t \$6 million, Stéphane Bouchard's 2-bedroom apartment is a little on the pricey side, especially considering the place is overrun with giant spiders. However, it does have hardwood floors. Even better, it can cure your fear of flying.

Technically, the apartment doesn't belong to Bouchard, but to the Université du Québec en Outaouais, in Gatineau, Quebec. And it isn't really an apartment, at least not the wood-and-drywall type. It's a 6-wall virtual reality "immersive room," the only of its kind in the world dedicated to clinical psychology.

The virtual 2-bedroom apartment is the first of many digital environments that Bouchard, who holds the Canada Research Chair in Clinical Cyberpsychology, and his research team plan on creating to study everything from gambling addiction to post-traumatic stress disorder. Bouchard's team - which includes graphic artists, computer engineers, video game designers and psychologists - is busy getting the immersive room ready for use in the fall.

"We are not developing new technologies," says Bouchard. "We are using current technologies and adapting them to treat, assess and understand mental disorders."

Bouchard, a psychologist, cofounded the cyberpsychology lab in 1999. It is also a treatment facility, though the immersive room will be strictly dedicated to research.

Controlled trials have shown that virtual reality is effective in treating some phobias, such as the fear of flying (J Consult Clin Psychol 2002;70:42832) and the fear of spiders (Behav Res
Ther 2002;40:983-93). A recent analysis of 21 studies of virtual reality exposure therapy indicates that it reduces anxiety and phobia symptoms, but called for more well-designed trials and better reporting of data $(J$ Behav Ther Exp Psychiatry 2008;39:250-61).

The technology is well suited for exposure therapy because it provides therapists complete control over a patient's environment. Settings can be tailored to individual patients, the dosage of exposure can be adjusted, and simulations can be paused and discussed. Patients are also guaranteed confidentiality, as they no longer have to face their fears in public settings. It is also cheaper to treat certain phobias, such as a fear of flying, with virtual reality.

Dr. Mark Wiederhold, president of Virtual Reality Medical Center in California, has been using virtual reality to

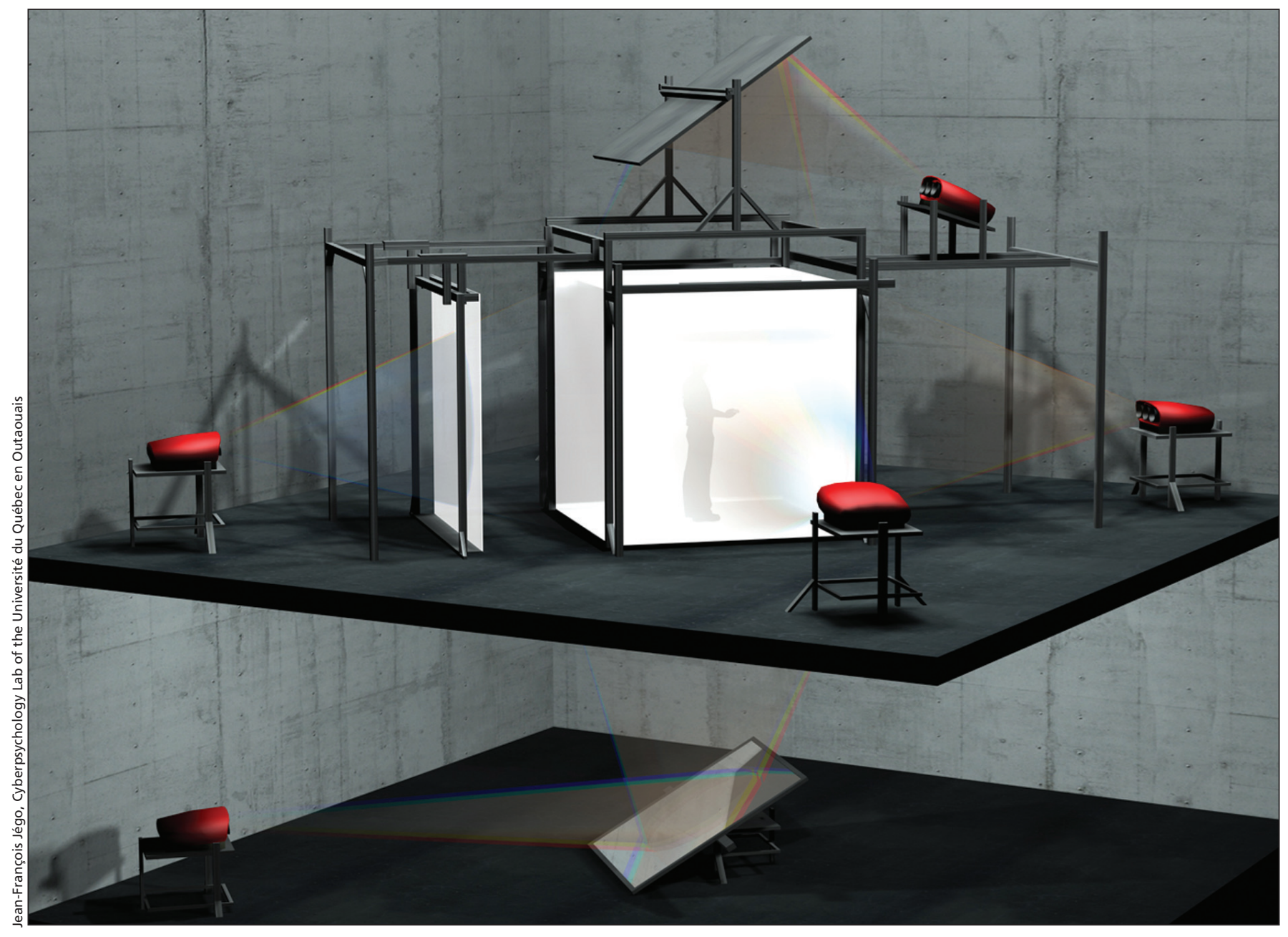

The Cyberpsychology Lab of the Université du Québec en Outaouais' 6-sided virtual reality "immersive room" has 4 vertical walls, 3 stationary and 1 sliding. Images are beamed onto the 2 horizontal walls via mirrors; the floor image is beamed up from the room below. 
treat phobias for 12 years. He believes the technology has proven valuable for research and has made for more affordable and effective mental health care, though he stresses that it is still just a tool. "The VR [virtual reality] is not going to make you a better clinician than you already are. The underlying, basic clinical skills learned in school need to be mastered."

Bouchard and his team began researching virtual reality exposure therapy in 2000. At the time, the cyberpsychology lab owned only virtual reality goggles, or head-mounted displays, which project images directly into a user's eyes.

Head-mounted displays are more affordable than immersive rooms, but are unable to create the same degree of realism. They provide a limited field of vision and don't allow users to see their own bodies while in a virtual environment. In 2005, Bouchard received funding for a 3-wall projection system. In January 2008, he received a grant from the Canadian Foundation for Innovation to upgrade that system to the $\$ 6$ million immersive room, which the lab has called PSYCHÉ. An immersive room, also known as a cave automatic virtual environment, is comprised of multiple square screens with sides about 3 metres in length. PSYCHÉ has 4 vertical screens, which serve as the walls of the virtual apartment, as well as 2 horizontal screens representing a floor and ceiling. Images are beamed onto each screen by its own projector, which is in turn operated by its own computer.

People undergoing therapy within the room are equipped with goggles that allow them to experience the virtual environment in 3 dimensions. The goggles also track movement, which enables the projectors to adjust images to reflect a patient's changing point of view.

Oddly enough, now that he has the technology to render realistic environments, Bouchard plans on using it to determine how much reality can be stripped away before virtual reality therapy becomes ineffective. The prevailing theory in cyberpsychology circles is that someone undergoing virtual reality therapy must feel a sense of presence - that is, they must feel as if they really are in, say, a plane or a

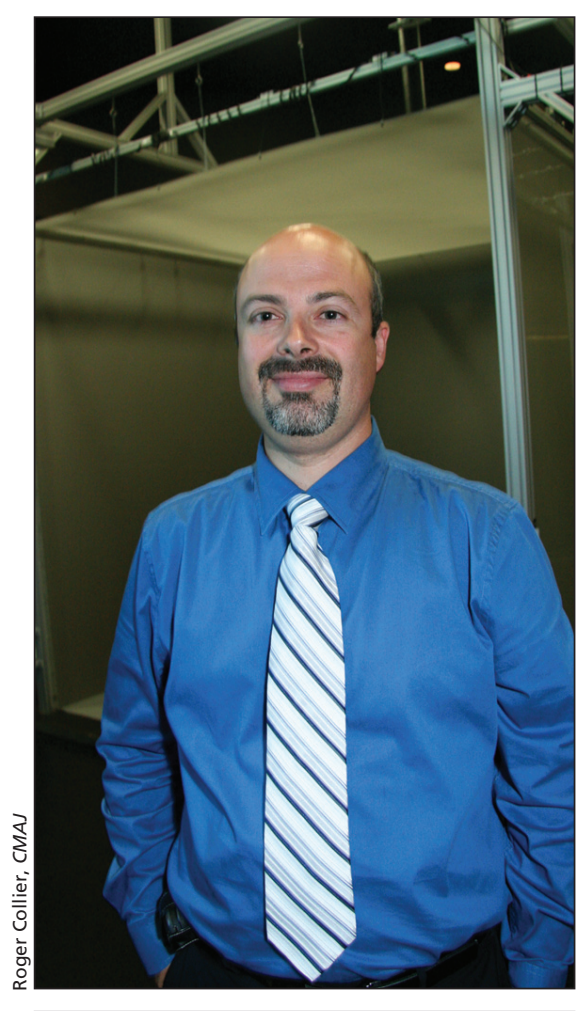

Stéphane Bouchard, the Canada Research Chair in Clinical Cyberpsychology, runs the only 6-wall virtual reality "immersive room" in the world dedicated to clinical psychology.

room full of spiders - in order for the treatment to work.

In some cases, Bouchard believes, that may not be true. To treat simple anxiety disorders, for example, the environment only needs to trigger the anxiety; certain other details may not be necessary.

"You don't need a perfect replica of reality, you need just enough," says Bouchard. "We are trying to figure out what just enough is."

Virtual reality has yet to be proven effective in treating complex problems, like post-traumatic stress disorder and obsessive-compulsive disorder. In time, however, Bouchard believes virtual reality researchers will succeed in creating the complex digital worlds needed to treat even the most complicated of mental disorders, though it may not be easy.

"There are so many situations that can trigger anxiety, so that is more of a challenge." - Roger Collier, CMAJ

DOI:10.1503/cmaj.081119

\section{Big pharma and good}

\section{corporate citizenship}

$\mathrm{T}$ he World Health Organization says that improving access to important and lifesaving medicines could save as many as 10 million lives a year. Yet in a world where a billion people live on less than $\$ 1$ a day, and important medicines consume a growing portion of the incomes of the planet's most destitute, there are no benchmarks that reveal the accessibility of medicines to the most poor. The impact of company policies on the availability of patented products in poor countries is largely unknown and it's all but a total mystery as to how much of a company's research budget is spent on discovering cures for diseases that affect the poor.

Until now, that is.

At least, that's the hope of the developers of a recently minted social responsibility index (http://atmindex. org/) that will track and measure the efforts of individual drug companies in ensuring that access to effective and affordable medicine is part of their corporate business plan.

Launched in June 2008, the index was established by the Access to Medicine Foundation, based in the Netherlands, which aims to raise awareness of the vital issue of global access to medicine by ranking 20 of the world's largest drug companies by how well they perform around 28 key indicators grouped into 8 main criteria. Those include patents, philanthropy, research and development, and pricing (Box 1). The upshot will be an "at-a-glance" snapshot of a company's social responsibility record.

Wim Leereveld, the founder and chief executive officer of the index, sees his initiative as being all about transparency. "What gets measured gets managed," he told CMAJ in an email interview. As each company becomes "transparent in what they do, or don't do, their roles will be much clearer and they will hopefully set and achieve goals for access to medicine for all."

Leereveld adds that encouraging companies to meet these goals requires the involvement of many stakeholders including governments, experts, nongovernmental organizations and others. 